\title{
Cyathostomine egg reappearance period following ivermectin treatment in a cohort of UK Thoroughbreds
}

\author{
Rebecca A. Molena ${ }^{1 \dagger}$, Laura E. Peachey ${ }^{1 \dagger}$, Angela Di Cesare ${ }^{2}$, Donato Traversa ${ }^{2}$ and Cinzia Cantacessi ${ }^{1 *}$ (D)
}

\begin{abstract}
Background: In spite of the emergence of populations of drug-resistant cyathostomines worldwide, little is known of parasite species responsible for 'early egg shedding' in cohorts of horses subjected to treatment with widely used anthelmintics, e.g. ivermectin (IVM). In this study, we determined the cyathostomine egg reappearance period (ERP) after IVM treatment in a cohort of yearlings from a large Thoroughbred (TB) stud farm in the United Kingdom, and identified species of cyathostomines with reduced ERP using a combination of fundamental parasitology techniques coupled with advanced molecular tools.

Methods: Individual faecal samples were collected from TB yearlings with cyathostomine infection prior to IVM treatment, as well as at 14, 21, 28, 35, 42 and 49 days post-treatment. Faecal egg counts (FEC) were performed for each individual sample for determination of ERPs. In addition, individual larval cultures were performed and representative numbers of third-stage larvae (L3s) harvested from each culture were subjected to molecular species identification via PCR-Reverse Line Blot (RLB).
\end{abstract}

Results: Prior to IVM treatment, 11 cyathostomine species were detected in faecal samples from TB horses enrolled in this study, i.e. Cyathostomum catinatum, Cylicostephanus longibursatus, Cylicostephanus goldi, Cylicocyclus nassatus, Cylicostephanus calicatus, Cyathostomum pateratum, Cylicocyclus radiatus, Paraposteriostomum mettami, Coronocyclus labratus, Cylicocyclus insigne and Cylicocyclus radiatus variant A. Of these, eggs of Cya. catinatum, Cys. longibursatus, Cyc. nassatus and Cyc. radiatus could be detected at 28 days post-treatment, while from day 42 onwards, cyathostomine species composition reflected data obtained pre-IVM treatment, with the exception of eggs of Cor. labratus and Cyc. insigne which could no longer be detected post-IVM administration.

Conclusions: This study provides valuable data on the occurrence of IVM-resistance in cyathostomines in the UK. Nevertheless, further investigations are needed to shed light on the prevalence and incidence of drug-resistance in this country, as well as other areas of the world where equine trade is substantial.

Keywords: Cyathostominae, Ivermectin, Anthelmintic resistance, Macrocyclic lactones, Egg reappearance period, Reverse line blot

\footnotetext{
* Correspondence: cc779@cam.ac.uk

${ }^{\dagger}$ Equal contributors

${ }^{1}$ Department of Veterinary Medicine, University of Cambridge, Cambridge, UK

Full list of author information is available at the end of the article
} 


\section{Background}

Intestinal nematodes of the subfamily Cyathostominae (family Strongylidae), also known as 'cyathostomins' or 'small strongyles' are ubiquitous parasites of equines, with reported prevalences of up to $100 \%$ in many regions of the world, including Europe and North America [1-4]. The subfamily currently includes 52 recognised species [5-7], characterised by a direct (oro-faecal), nonmigratory life-cycle. Adult males and females live in the lumen of the large intestine, where the latter shed eggs that are excreted in the environment with the host faeces; under suitable conditions of temperature and humidity, first-stage larvae (L1s) hatch from the eggs and develop through to second- (L2s) and third-stage larvae (L3s, the infective stages) [8]. These are ingested by susceptible equine hosts while grazing, and move to the large intestine where they become encysted within the mucosal layer and mature to fourth-stage larvae (L4s) [9]. Alternatively, within the mucosa, L3s can undergo hypobiosis and survive up to 2.5 years before resuming their development [10]. Subsequently, L4s emerge from the cysts and migrate to the intestinal lumen, where they undergo their final development to adult males and females [11]. The pre-patent period ranges from 5 to 12 weeks depending on parasite species [12].

While infections by cyathostomines often remain subclinical, clinical signs associated with heavy parasite burdens may occur, particularly in young, geriatric and immunocompromised equines [13, 14]. In particular, the synchronous emergence of L4s into the intestinal lumen may be accompanied by a protein losing enteropathy characterized by a sudden onset of diarrhoea, weight loss and dehydration ('larval cyathostominosis'), that can prove fatal in $50 \%$ of cases [15-17]. Additionally, nonspecific weight loss, non-strangulating infarction, tympanic colic and mild non-specific colic have been observed in horses infected by large numbers of worms [13, 18-23].

Traditionally, cyathostomine infections are controlled via the regular administration of parasiticides, i.e. 'anthelmintics.' Currently licenced anthelmintics with efficacy against cyathostomines include the benzimidazoles (BZ), e.g. fenbendazole (FBZ) [24, 25], the tetrahydropyrimidines (THP), e.g. pyrantel pamoate (PYR) $[26,27]$ and the macrocyclic lactones (ML), e.g. ivermectin (IVM) and moxidectin (MOX) [28-30]. However, the widespread and indiscriminate use of these chemotherapeutics has led to the emergence of populations of cyathostomines resistant to all of these drugs [31-34]. In particular, anthelmintic resistance (AR) of cyathostomine populations to BZs is widespread [35-40], whilst resistance to PYR is common in some regions [37-39, 41-43]. Therefore, given that none of the novel anthelmintics used in other veterinary species developed over the last decade are licenced for use in horses [44], current deworming programs aimed to control cyathostomine infections rely upon ML compounds. Amongst these, IVM and MOX are used interchangeably; nevertheless, the relative high cost of MOX compared to IVM [45], as well as ongoing efforts to preserve its efficacy against encysted larvae (by avoiding its excessive use) [36, 46], make IVM the most widely used anthelmintic against cyathostomine infections.

Regrettably, the widespread use of ML has been accompanied by reports of emerging AR in cyathostomine populations globally, primarily evidenced by a reduction in egg reappearance period (ERP) (i.e. the time between administration of anthelmintics and the detection of parasite eggs in faeces) [38, 42, 47-53]. Reduced ERPs have been associated with the survival of luminal L4 stages, that reach sexual maturity before encysted L4s and/or newly ingested L3s [54]. However, in spite of these reports, little evidence of AR to IVM in cyathostomine populations based on faecal egg count reduction test (FECRT) analyses is available [47, 51, 52]. Further investigations are therefore needed to better understand the occurrence of AR to IVM in cyathostomine populations, and to design strategies to prevent and/or mitigate its spread. In order to achieve this outcome, knowledge of the fundamental biology of cyathostomines, and in particular of species responsible for 'early egg shedding', is necessary. Thus far, only four studies have provided data on species of cyathostomines responsible for reduced ERPs after IVM and MOX treatment in Europe $[55,56]$ and the USA $[57,58]$. Although the findings from these studies were largely similar, some differences were observed, likely due to variations in cyathostomine species epidemiology between geographical locations. Additional studies conducted in a range of countries, characterised by different epidemiologies of cyathostomine infections, may help elucidate these issues. In particular, given the substantial contribution that the Thoroughbred (TB) racehorse industry provides to the economy of the United Kingdom, AR is of particular concern. In this study, we determined the ERP after IVM treatment in a cohort of yearlings from a large TB stud farm in the UK and identified species of IVM-'resistant' cyathostomines using a combination of fundamental parasitology techniques coupled with advanced molecular tools.

\section{Methods}

\section{Sample collection}

Sample collection was performed between April and June 2017. A cohort of 54 TB yearlings housed in a stud farm in the south-east of England was initially screened for this study. In particular, all yearlings had been treated with FBZ (Panacur 18.75\% FBZ, MSD, Milton Keynes, 
UK) and IVM (Eqvalan, 1.87\% IVM, Merial, Harlow, UK) approximately 10 weeks prior to the beginning of the study, and with praziquantel (PZQ) (Equitape, $90 \mathrm{mg} / \mathrm{g}$ PZQ, Zoetis, Tadworth, UK) 3 weeks prior to the start of the study, respectively. On Day 0 (D0), freshly-voided faecal samples were collected from individual horses and subsequently screened for infections by parasitic nematodes using a centrifugal floatation faecal egg count (FEC) technique sensitive to 1 egg per gram (EPG) [59]. Samples were also screened for tapeworm infections (by Anoplocephala spp.) using a standard double sugar flotation technique [60]. Immediately after sampling, all animals were treated with $0.2 \mathrm{mg} / \mathrm{kg}$ of IVM (Eqvalan', Merial, Harlow, UK). Horses with FEC $>75$ strongyle EPG were selected for the study. From these, additional faecal samples were collected weekly up to 7 weeks post-IVM treatment and subjected to faecal examination as described above.

\section{Faecal egg count reduction test (FECRT) and determination of egg reappearance period (ERP)}

Arithmetic means of FEC values obtained from individual faecal samples at D0 and Day 14 (D14) were used to estimate faecal egg count reduction (FECR), using guidelines established by the World Association for Advancement of Veterinary Parasitology [61], according to the formula:

$F E C R \%=\frac{E P G(\text { pre-treatment })-E P G(\text { post-treatment })}{E P G(\text { pre-treatment })} \times 100$

A FECR of $<95 \%$ with $95 \%$ lower confidence limits (LCL) was considered to indicate potential AR, according to previously published recommendations [62, 63]. In this study, the ERP was defined as the first time point (post-IVM treatment) at which a mean FEC that exceeded $10 \%$ of the mean FEC at D0 was observed [42, 64]. Statistical analyses were performed using Microsoft Office Excel 2013.

\section{Larval culture and harvest of cyathostomine larvae}

In order to identify species of cyathostomines with reduced ERP post-IVM treatment, faecal samples containing cyathostomine eggs were subjected to larval culture as described by van Doorn et al. [55]. Briefly, individual faecal samples were placed in open trays at room temperature for 14 days. Following incubation, L3s were collected using the Baermann's apparatus, washed three times with distilled water, centrifuged at $14,000 \times \mathrm{rpm}$ for $5 \mathrm{~min}$ and re-suspended in $1 \mathrm{ml} \mathrm{100 \%}$ ethanol before storing at $-20{ }^{\circ} \mathrm{C}$.

Nucleic acid extraction and polymerase chain reactionreverse line blot (PCR-RLB)

From each faecal sample, four representative pools, each containing 10 larvae, were prepared according to the method described by Kooyman et al. [56]; this method has been proven accurate for the semi-quantitative determination of cyathostomine species composition in a given sample [56]. Briefly, aliquots of L3s from each sample were placed on individual Petri dishes and observed under a stereomicroscope; for each of these, 40 larvae were picked using a wide orifice tip and transferred to four $1.5 \mathrm{ml}$ centrifuge tubes (10 larvae in each tube). $73 \mu$ of proteinase $\mathrm{K}$ was added to $1 \mathrm{ml}$ of Worm Lysis Buffer (WLB) $(50 \mathrm{mM} \mathrm{KCl}, 10 \mathrm{mM}$ tris $\mathrm{pH} 8.3$, $2.5 \mathrm{mM} \mathrm{MgCl}_{2}, 0.45 \% \mathrm{NP}-40,0.45 \%$ tween-20 and $0.01 \%$ gelatin; ThermoFisher Scientific, Waltham, MA, USA; Sigma-Aldrich, St. Louis, MO, USA) [65] and $50 \mu$ l of Proteinase K/WLB solution was added to each L3 pool. Pools were incubated overnight at $56{ }^{\circ} \mathrm{C}$. Proteinase $\mathrm{K}$ was then inactivated by incubation at $95^{\circ} \mathrm{C}$ for $15 \mathrm{~min}$; lysates were stored at $-20{ }^{\circ} \mathrm{C}$ until further processing.

Identification of the species of cyathostomines present in each pool was performed using an established PCRRLB hybridisation method [66] with slight modifications [67]. Briefly, genomic DNA extracted from each pool of L3s was subjected to nested-PCR amplification of the intergenic spacer (IGS) region using biotin labelled primers [66]. The PCR products were then incubated with Biodyne $\mathrm{C}$ membrane bound specific DNA probes, using a Miniblotter 45 (Bioworld), for 21 different cyathostomine species and two conserved probes for the genus Strongylus and the subfamily Cyathostominae [66, 67], incubated with extravidin peroxidase (Sigma-Aldrich, St. Louis, MO, USA) and visualised using chemiluminescence detection.

\section{Results}

Of the 54 yearlings screened at D0, 11 had FEC $>75$ EPG and were therefore enrolled in this study (Additional file 1: Table S1). Strongyle FEC performed from samples collected from individual horses at D0 (preIVM treatment), and at D14, D28, D35, D42 and D49 post-IVM treatment, as well as corresponding means, are shown in Additional file 1: Table S1 and Fig. 1. At D14, a 100\% FECR was observed in all 11 horses enrolled in the study, whereas the numbers of strongyle eggs in individual faecal samples exceeded the set threshold for ERP at D28 in Horse 8, D35 in Horses 1, 4, 6, 7, 9, and 11, D42 in Horses 3 and 10 and D49 in Horses 2 and 5 (Additional file 1: Table S1 and Fig. 1).

Prior to IVM treatment, larval culture of individual samples collected from horses enrolled in this study, coupled with PCR-RLB for species identification, revealed infections by 11 cyathostomine species. In decreasing order of frequency of detection per horse, these were Cyathostomum catinatum, Cylicostephanus longibursatus, Cylicostephanus goldi, Cylicocyclus nassatus, Cylicostephanus calicatus, Cyathostomum pateratum, Cylicocyclus 


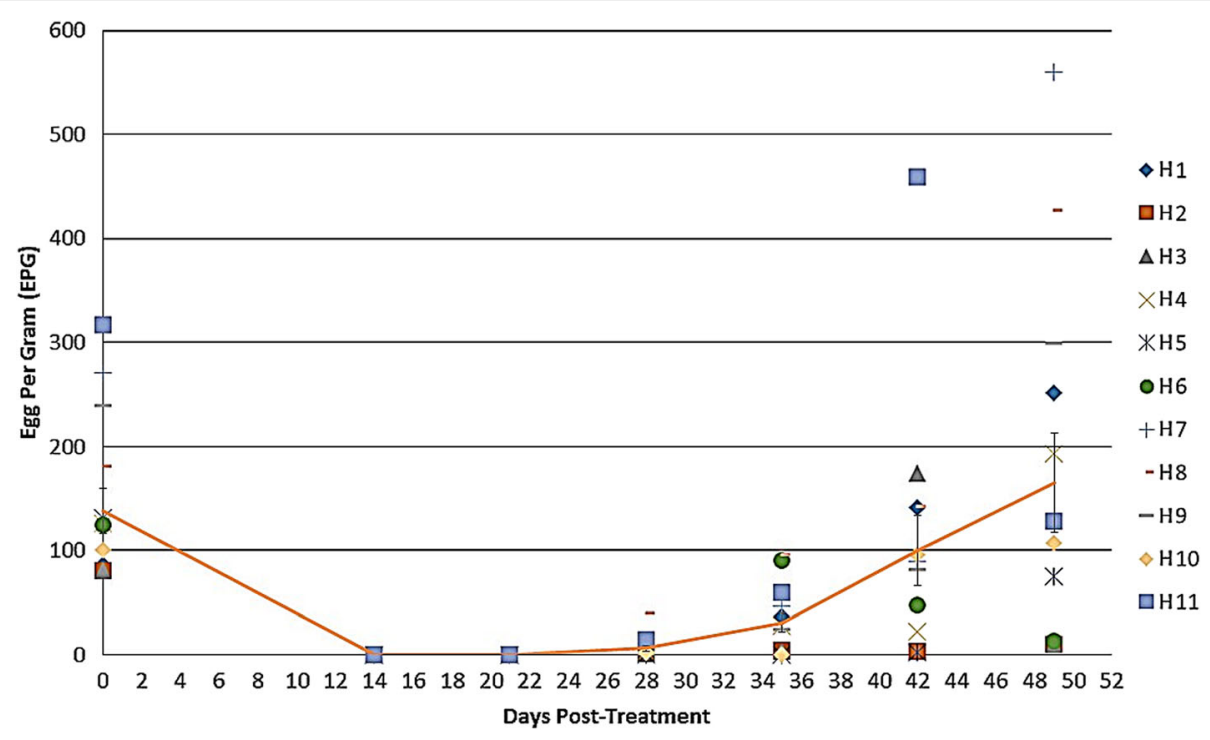

Fig. 1 Mean faecal egg counts (FEC) recorded for each horse (H) enrolled in the study, prior to ivermectin administration (D0), as well as at D14, D21, D28, D35, D42 and D49, following anthelmintic treatment

radiatus, Paraposteriostomum mettami, Coronocyclus labratus, Cylicocyclus insigne and Cylicocyclus radiatus variant A (Fig. 2). One additional species, Coronocyclus coronatus, was detected post-IVM treatment at D35, D42 and D49 (Fig. 2). Species of cyathostomines detected in faecal samples from individual horses post-IVM treatment via RLB are listed in Fig. 2. The first species detected posttreatment, at D28, were Cya. catinatum (in five horses), Cys. longibursatus (in five horses), Cyc. nassatus (in three horses) and Cyc. radiatus (in one horse) (Fig. 2). At Day 35, a total of 7 species were detected in a total of 8 horses, i.e. those detected at D28 (except Cyc. radiatus variant A) together with Cys. calicatus, Cya. pateratum, P. mettami and Cor. coronatus; in particular, the latter was not detected amongst species identified pre-IVM treatment (Fig. 2). Eggs of Cys. goldi reappeared in one horse from D42, while those of Cor. labratus and Cyc. insigne were no longer detected post-IVM treatment (Fig. 2). From D42 onwards, cyathostomine species composition reflected data obtained preIVM treatment (Fig. 2).

\section{Discussion}

The acquisition of comprehensive data on the occurrence and prevalence of potential drug-resistant species of cyathostomine is the necessary basis on which to build studies aimed to unravel the fundamental molecular biology of AR in this complex group of nematodes, as well as to develop and test new chemotherapeutics and/or alternative strategies for parasite control. In this study, we aimed to determine the ERP of cyathostomines following treatment with IVM, and to identify the species responsible for 'early egg shedding'. Specifically, the ERP was defined as the earliest time point post-IVM treatment in which the number of EPG obtained following FEC analysis of samples collected from individual horses was $\geq 10 \%$ of the corresponding number observed pre-anthelmintic treatment [42, 64]. This definition was selected to minimise errors associated with the sensitivity of the FEC technique used that, although reported to be as low as 1 EPG [59], does not allow to unequivocally rule-out false negative results.

Data obtained from the FECRT suggest that the administration of IVM was effective in eliminating adult populations of cyathostomines 14 days post-treatment; nevertheless, the ERP was shorter than that originally reported for an IVM-susceptible population of parasites (i.e. 8-13 weeks) $[68,69]$. Whilst 9 out of 11 horses had detectable strongyle eggs at D28, FECs in all of these horses but one were below 10\% of the FEC recorded pre-treatment, thus failing to reach the set threshold of ERP at this time-point. In seven of these horses, FECs above the ERP threshold were subsequently observed at D35 post-IVM treatment. This is in agreement with the majority of recent reports from Europe and the USA, in which strongyle eggs were detected from 28 days postIVM treatment [52, 55, 57, 70, 71]. This data suggests that populations of IVM-resistant cyathostomines are indeed developing in the TB stud farm where the investigation was carried out, and that overt AR will likely emerge in future, should the current regime of IVM administration continue. Indeed, it must be pointed out that, in the stud farm under consideration, IVM and MOX are regularly administered (in rotation) to horses with $>50$ EPG. While aimed to provide 'targeted' treatments to horses with relatively high infection intensity, this practice may facilitate the emergence of AR by 


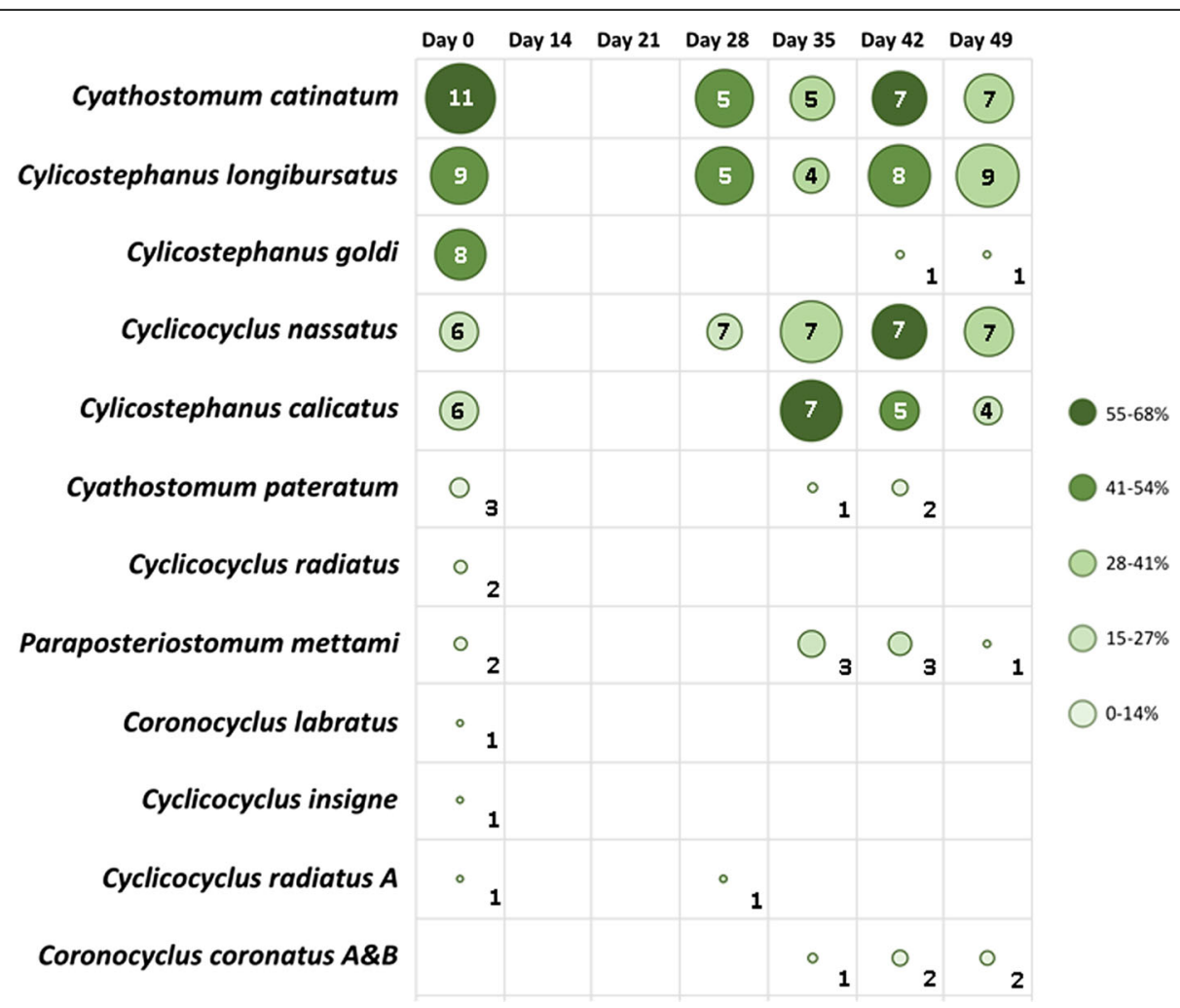

Fig. 2 Species of cyathostomine identified from larval cultures of horses enrolled in this study, prior to (D0) and following ivermectin administration (D14, D21, D28, D35, D42 and D49, respectively). Bubble sizes correspond to the relative proportions of horses infected with the corresponding species, while the exact number (out of a total of 11 horses enrolled in the study) is indicated within the circle/cell. Shades of green indicate the percentage of larval pools (see Methods) from which the corresponding species was identified

preventing the development and maintenance of refugia of susceptible parasites [72]. Thus, a threshold of $>200$ EPG for treatment administration, combined with strategies of environmental control aimed to reduce the numbers of free-living larvae on the pasture (e.g. by bi-weekly removal of faecal matter; cf. [73, 74]) may assist in slowing the process of developing AR in these parasite populations [74, 75].

Prior to IVM-treatment, the most prevalent species of cyathostomines in the TB population under investigation were, in decreasing order of prevalence, Cya. catinatum, Cys. longibursatus, Cys. goldi and Cyc. nassatus. With the exception of Cys. goldi, whose eggs could not be detected until D42 post-IVM treatment, eggs from these species were observed at D28 in 10 out of 11 horses, albeit the corresponding FEC did not reach the set ERP threshold. These findings are supported by data from earlier studies that report cyathostomine species with a relatively high prevalence pre-IVM and MOX administration to display a reduced ERP of 4-5 weeks postIVM, 4 weeks post-MOX [57, 58, 76] and 'anthelmintic resistance' [54]. One possible explanation is technical, and linked to the high relative proportion of these species in faecal samples from horses pre- and post- anthelmintic treatment; indeed, given that species identification via the RLB technique used in this study relies on a randomly selected (representative) sub-population of L3s, the likelihood of eggs from a given species to be successfully identified is directly correlated to its initial prevalence in the sample under consideration. In contrast to this hypothesis, van Doorn et al. [55] reported that, regardless of species prevalence prior to treatment, eggs of Cylicocyclus spp. were consistently detected prior to those of other species post-IVM treatment [55]. Interestingly, in spite of the relatively high prevalence of Cys. goldi in horses pre-treatment here (i.e. 6/11), eggs of this species could not be detected in faecal samples until D42 post-IVM treatment, thus indicating greater susceptibility of this species to IVM. This observation contrasts findings from Ionita et al. [57], that reported a (postIVM) ERP for Cys. goldi of 5 weeks. Given that the molecular events that determine the emergence of $A R$ in cyathostomines are, thus far, poorly understood (with mutations of the $\alpha$-subunit gene of a $\mathrm{GluCl}$ channel [77, $78]$, reduction in drug uptake $[79,80]$ and overexpression of parasite P-glycoproteins (P-gps) [81, 82], all proposed as potential underlying mechanisms), the identification of susceptible (e.g. Cys. goldi) and resistant 
species of cyathostomines (e.g. Cya. catinatum, Cys. longibursatus), may provide a suitable platform for future studies aimed to investigate the molecular basis of cyathostomine $\mathrm{AR}$, at the DNA, mRNA and protein level.

At D42 and D49 post-IVM treatment, the cyathostomine species composition observed in faecal samples via RLB largely reflected that of pre-IVM, with the exception of Cor. labratus and Cyc. insigne, whose eggs were no longer detected post-anthelmintic administration. In addition, at D35, eggs of Cor. coronatus were detected in one horse; this species had not been identified from samples pre-IVM. The low prevalence of Cor. labratus and Cyc. insigne species pre-IVM administration (1/11 horses), as well as the likely low proportion of Cor. coronatus in samples pre-treatment, may have led to L3s of these species not being selected amongst those that underwent PCR-RLB screening (see also [83]). Indeed, while this method represents a faster and relatively inexpensive alternative to sequencing of DNA amplicons from individual larvae (which is unfeasible under natural conditions of infection, when hundreds to thousands of larvae can develop in faecal samples from horses with heavy parasite burdens), its intrinsic limitation consists in the inability to unequivocally rule out the presence of other, less represented species of cyathostomines in the initial faecal sample. Nevertheless, in the future, the study of the 'nemabiome' (i.e. the characterisation of whole parasite communities within a given sample via high-throughput amplification and sequencing of nematode genetic loci [84]) of faecal samples from horses prior to and postanthelmintic treatment, will provide the scientific community with means to overcome this constraint.

\section{Conclusions}

While this study provides valuable data on the occurrence of IVM-resistance in the UK, further investigations are needed to shed light on the prevalence and incidence of drug-resistance in this country, as well as other areas of the world where equine trade is substantial. Primarily, it should be established whether our observation that the most prevalent species of cyathostomines are responsible for shortened ERPs, are consistent across different geographical areas, or whether emergence of AR is dependent on specific micro-climatic and/or epidemiological conditions. This information is indeed crucial to inform future strategies aimed to mitigate the occurrence and spread of AR.

\section{Additional file}

Additional file 1: Table S1. Raw faecal egg count (FEC) data collected from individual horses enrolled in this study, prior to ivermectin (IVM)treatment, as well as at Day (D) 14, 21, 28, 35, 42 and 49 post-treatment. (DOCX $25 \mathrm{~kb}$ )

\section{Abbreviations}

AR: Anthelmintic resistance; BZ: Benzimidazole; Cya.: Cyathostomum; Cyc:: Cylicocyclus; Cys.: Cylicostephanus; EPG: Eggs per gram; ERP: Egg reappearance period; FBZ: Fenbendazole; FEC: Faecal egg count; FECR: Faecal egg count reduction; FECRT: Faecal egg count reduction test; IVM: Ivermectin; ML: Macrocyclic lactones; MOX: Moxidectin; PYR: Pyrantel; PZQ: Praziquantel; RLB: Reverse Line Blot; TB: Thoroughbred;

THP: Tetrahydropyrimidines; WLB: Worm Lysis Buffer

\section{Acknowledgements}

The authors wish to thank the owners and staff of the stud farm from which samples were collected for their assistance throughout. Also, our sincere thanks go to Ms Xiaopei Su for technical assistance.

\section{Funding}

LEP is the grateful recipient of a Postdoctoral Fellowship by the Horserace Betting Levy Board of the United Kingdom.

\section{Availability of data and materials}

Data obtained in this study are accessible from Tables and Figures included in this article.

\section{Authors' contributions}

RAM, LEP and CC conceived the study; RAM, LEP, ADC and DT participated in the development of the protocol; RAM, LEP and CC wrote the manuscript. All authors read and approved the final manuscript.

\section{Ethics approval and consent to participate}

This study was approved and carried out in strict accordance and compliance with the guidelines of the Institutional Ethical Review Committee, Department of Veterinary Medicine, University of Cambridge, UK (Research Project No. CR190). Written informed consent was obtained from the stud farm from which study samples were collected.

Consent for publication

Not applicable.

\section{Competing interests}

The authors declare that they have no competing interests.

\section{Publisher's Note}

Springer Nature remains neutral with regard to jurisdictional claims in published maps and institutional affiliations.

\section{Author details}

${ }^{1}$ Department of Veterinary Medicine, University of Cambridge, Cambridge, UK. ${ }^{2}$ Faculty of Veterinary Medicine, University of Teramo, Località Piano d'Accio, Teramo, Italy.

Received: 7 November 2017 Accepted: 10 January 2018

Published online: 25 January 2018

\section{References}

1. Mfitilodze MW, Hutchinson GW. Prevalence and abundance of equine strongyles (Nematoda: Strongyloidea) in tropical Australia. J Parasitol. 1990; 76:487-94.

2. Collobert-Laugier $\mathrm{C}$, Hoste $\mathrm{H}$, Sevin $\mathrm{C}$, Dorchies P. Prevalence, abundance and site distribution of equine small strongyles in Normandy, France. Vet Parasitol. 2002;110:77-83.

3. Hinney B, Wirtherle NC, Kyule M, Miethe N, Zessin KH, Clausen PH. Prevalence of helminths in horses in the state of Brandenburg, Germany. J Parasitol Res. 2011:108:1083-91.

4. Morariu S, Mederle N, Badea C, Dărăbuş G, Ferrari N, Genchi C. The prevalence, abundance and distribution of cyathostomins (small strongyles) in horses from western Romania. Vet Parasitol. 2016;223:205-9.

5. Lichtenfels JR, Kharchenko VA, Krecek RC, Gibbons LM. An annotated checklist by genus and species of 93 species level names for 51 recognised species of small strongyle (Nematoda: Strongyloidea: Cyathostominea) of horses, asses and zebras of the world. Vet Parasitol. 1998;79:65-79. 
6. Lichtenfels JR, Gibbons LM, Krecek RC. Recommended terminology and advances in the systematics of the Cyathostominea (Nematoda: Strongyloidea) of horses. Vet Parasitol. 2002;107:337-42.

7. Matthee S, Krecek RC, Gibbons LM. Cylicocyclus asini n. sp. (Nematoda: Cyathostominae) from donkeys Equus asinus in South Africa. Syst Parasitol. 2002:51:29-35

8. Ogbourne CP. Observations on the free-living stages of strongylid nematodes of the horse. Parasitology. 1972;64:461-77.

9. Chapman MR, Kearney MT, Klei TR. An experimental evaluation of methods used to enumerate mucosal cyathostome larvae in ponies. Vet Parasitol. 1999;86:191-202

10. Gibson TE. The effect of repeated anthelmintic treatment with phenothiazine on the faecal egg counts of housed horses, with some observations on the life cycle of Trichonema spp. in the horse. J Helminthol. 1953:27:29-40.

11. Corning S. Equine cyathostomins: a review of biology, clinical significance and therapy. Parasit Vectors. 2009;2 Suppl 2:S1.

12. Love S, Duncan JL. The development of naturally acquired cyathostome infection in ponies. Vet Parasitol. 1992:44:127-42.

13. Love S, Murphy D, Mellor D. Pathogenicity of cyathostome infection. Vet Parasitol. 1999;85:113-21.

14. Kornas S, Cabaret J, Skalska M, Nowosad B. Horse infection with intestinal helminths in relation to age, sex, access to grass and farm system. Vet Parasitol. 2010;174:285-91.

15. Mirck M. Cyathostominose: een vorm van ernstige Strongylidose. Tijidsschrift Diergeneesk. 1977;102:876-8.

16. Ogbourne C. Pathogenesis of cyathostome Trichonema infections of the horse. A review. Farnham Royal, Slough: Commonwealth Agricultural Bureau; 1978. p. 25.

17. Giles CJ, Urquhart KA, Longstaffe JA. Larval cyathostomiasis (immature Trichonema-induced enteropathy): a report of 15 clinical cases. Equine Vet J. 1985:17:196-201.

18. Uhlinger $C$. Effects of three anthelmintic schedules on the incidence of colic in horses. Equine Vet J. 1990:22:251-4.

19. Mair TS, Pearson GR. Multifocal non-strangulating intestinal infarction associated with larval cyathostomiasis in a pony. Equine Vet J. 1995;27:154-5.

20. Mair TS, Sutton DG, Love S. Caecocaecal and caecocolic intussusceptions associated with larval cyathostomosis in four young horses. Equine Vet J. 2000;32:77-80.

21. Khan M, Roohi N, Rana M. Strongylosis in equines: a review. J Anim Plant Sci. 2015;25:1-9.

22. Bland S. Equine colic: a review of the equine hindgut and colic. Vet Sci Dev. 2016;6223:48-51.

23. Debeffe L, Mcloughlin PD, Medill SA, Stewart K, Andres D, Shury T, et al. Negative covariance between parasite load and body condition in a population of feral horses. Parasitology. 2016;143:983-97.

24. Baker NF, Douglas JR. Critical trials with thiabendazole as an anthelmintic in the gastrointestinal tract of cattle and sheep. Am J Vet Res. 1962;23:1219-23.

25. Bell RR, Galvin TJ, Turk RD. Anthelmintics for ruminants. VI Thiabendazole Am J Vet Res. 1962;23:195-200.

26. Lyons ET, Drudge JH, Tolliver SC, Breukink HJ. Critical test of three salts of pyrantel against internal parasites of the horse. Am J Vet Res. 1974;35:1515-22.

27. Slocombe JO, Smart J. Evaluation of pyrantel pamoate against strongyles in horses. Can Vet J. 1975:16:310-2.

28. Campbell WC, Fisher MH, Stapley EO, Albers-Schonberg G, Jacob TA. Ivermectin: a potent new antiparasitic agent. Science. 1983;221:823-8.

29. Slocombe JO, Cote JF. Effectiveness of ivermectin paste for removal of nematodes in the horse. Can Vet J. 1984;25:386-8.

30. Lyons ET, Tolliver SC, Drudge JH, Granstrom DE, Collins SS, Stamper S. Critical and controlled tests of activity of moxidectin (CL 301,423) against natural infections of internal parasites of equids. Vet Parasitol. 1992:41:255-84.

31. Matthews JB. An update on cyathostomins: anthelmintic resistance and worm control. Equine Vet Educ. 2008;20:552-60.

32. Stratford $\mathrm{CH}, \mathrm{McGorum} \mathrm{BC}$, Pickles KJ, Matthews JB. An update on cyathostomins: anthelmintic resistance and diagnostic tools. Equine Vet J. 2011:43:133-9.

33. Peregrine AS, Molento MB, Kaplan RM, Nielsen MK. Anthelmintic resistance in important parasites of horses: does it really matter? Vet Parasitol. 2014:201:1-8.

34. Tzelos T, Matthews JB. Anthelmintic resistance in equine helminths and mitigating its effects. In Pract. 2016:38:489-99.

35. Kaplan RM, Klei TR, Lyons ET, Lester G, Courtney CH, French DD, et al. Prevalence of anthelmintic resistant cyathostomes on horse farms. J Am Vet Med Assoc. 2004;225:903-10.
36. Lind E, Rautalinko E, Uggla A, Waller P, Morrison D, Hoglund J. Parasite control practices on Swedish horse farms. Acta Vet Scand. 2007:49:25.

37. Traversa D, Klei TR, lorio R, Paoletti B, Lia RP, Otranto D, et al. Occurrence of anthelmintic resistant equine cyathostome populations in central and southern Italy. Prev Vet Med. 2007;82:314-20.

38. Traversa D, von Samson-Himmelstjerna G, Demeler J, Milillo P, Schurmann S, Barnes $\mathrm{H}$, et al. Anthelmintic resistance in cyathostomin populations from horse yards in Italy, United Kingdom and Germany. Parasit Vectors. 2009; 2(Suppl. 2):S2

39. Traversa D, Castagna G, von Samson-Himmelstjerna G, Meloni S, Bartolini R, Geurden T, et al. Efficacy of major anthelmintics against horse cyathostomins in France. Vet Parasitol. 2012;188:294-300.

40. Lester HE, Spanton J, Stratford CH, Bartley DJ, Morgan ER, Hodgkinson JE, et al. Anthelmintic efficacy against cyathostomins in horses in southern England. Vet Parasitol. 2013:197:189-96.

41. Lyons ET, Tolliver SC, Drudge JH, Collins SS, Swerczek TW. Continuance of studies on population $\mathrm{S}$ benzimidazole-resistant small strongyles in a Shetland pony herd in Kentucky: effect of pyrantel pamoate (1992-1999). Vet Parasitol. 2001:94:247-56.

42. Nielsen M, Mittel L, Grice A, Erskine M, Graves E, Vaala W, et al. AAEP Parasite Control Guidelines. 2013. Available from: http://veterinaryextension.colostate. edu/menu2/equine/AAEPparasitecontrol13.pdf. Accessed 7 Mar 2017.

43. Stratford $\mathrm{CH}$, Lester HE, Pickles KJ, McGorum BC, Matthews JB. An investigation of anthelmintic efficacy against strongyles on equine yards in Scotland. Equine Vet J. 2014;46:17-24.

44. Epe C, Kaminsky R. New advancement in anthelmintic drugs in veterinary medicine. Trends Parasitol. 2013;29:129-34.

45. Relf VE, Morgan ER, Hodgkinson JE, Matthews JB. A questionnaire study on parasite control practices on UK breeding thoroughbred studs. Equine Vet J. 2012:44:466-71.

46. Nielsen MK, Monrad J, Olsen SN. Prescription-only anthelmintics - a questionnaire survey of strategies for surveillance and control of equine strongyles in Denmark. Vet Parasitol. 2006;135:47-55.

47. Molento MB, Antunes J, Bentes RN, Coles G. Anthelmintic resistant nematodes in Brazilian horses. Vet Rec. 2008;162:384-5.

48. Milillo P, Boeckh A, Cobb R, Otranto D, Lia RP, Perrucci S, et al. Faecal cyathostomin egg count distribution and efficacy of anthelmintics against cyathostomins in Italy: a matter of geography? Parasit Vectors. 2009;2(Suppl. 2):S4

49. Trawford AF, Burden FA, Hodgkinson J. Suspected moxidectin resistance in cyathostomes in two donkey herds at the donkey sanctuary, UK, vol. 196. Christchurch: Proceedings of the 20th International Conference of the World Association for Advancement in Veterinary Parasitology; 2005.

50. Nareaho A, Vainio K, Oksanen A. Impaired efficacy of ivermectin against Parascaris equorum, and both ivermectin and pyrantel against strongyle infections in trotter foals in Finland. Vet Parasitol. 2011;182:372-7.

51. Canever RJ, Braga PR, Boeckh A, Grycajuck M, Bier D, Molento MB. Lack of Cyathostomin sp. reduction after anthelmintic treatment in horses in Brazil. Vet Parasitol. 2013;194:35-9.

52. Relf $\mathrm{V}$, Lester $\mathrm{H}$, Morgan $\mathrm{E}$, Hodgkinson J, Matthews JB. Anthelmintic efficacy on UK thoroughbred stud farms. Int J Parasitol. 2014;44:507-14.

53. Tzelos T, Barbeito JS, Nielsen MK, Morgan ER, Hodgkinson JE, Matthews JB. Strongyle egg reappearance period after moxidectin treatment and its relationship with management factors in UK equine populations. Vet Parasitol. 2017:237:70-6.

54. Lyons ET, Tolliver SC, Collins SS. Probable reason why small strongyle EPG counts are returning "early" after ivermectin treatment of horses on a farm in Central Kentucky. Parasitol Res. 2009;104:569-74.

55. van Doorn D, Ploeger H, Eysker M, Geurden T, Wagenaar J. Cyclicocylus species predominate during shortened egg reappearance periods in horses after treatment with ivermectin and moxidectin. Vet Parasit. 2014;206:246-52.

56. Kooyman F, van Doorn D, Geurden T, Wagenaar J. Semi-quantitative differentiation of cyathostomin larval cultures by reverse line blot. Vet Parasitol. 2016:216:59-63.

57. Ionita M, Howe DK, Lyons ET, Tolliver SC, Kaplan RM, Mitrea IL, Yeargan M. Use of a reverse line blot assay to survey small strongyle (Strongylida: Cyathostominae) populations in horses before and after treatment with ivermectin. Vet Parasitol. 2010;168:332-7.

58. Bellaw JL, Krebs K, Reinemeyer CR, Norris JK, Scare JA, Pagano S, Nielsen MK. Anthelmintic therapy of equine cyathostomin nematodes - larvicidal efficacy, egg reappearance period, and drug resistance. Int J Parasitol. 2017; (in press) 
59. Bartley DJ, Donnan AA, Jackson E, Sargison N, Mitchell GB, Jackson F. A small scale survey of ivermectin resistance in sheep nematodes using the faecal egg count reduction test on samples collected from Scottish sheep. Vet Parasitol. 2006;137:112-8.

60. Rehbein S, Lindner T, Visser M, Winter R. Evaluation of a double centrifugation technique for the detection of Anoplocephala eggs in horse faeces. J Helminthol. 2011;85:409-14.

61. Coles G, Bauer C, Borgsteede F, Geerts S, Klei T, Taylor M, Waller P. World Association for the Advancement of Veterinary Parasitology (WAAVP) methods for the detection of anthelmintic resistance in nematodes of veterinary importance. Vet Parasitol. 1992;44:35-44.

62. Vidyashankar AN, Kaplan RM, Chan S. Statistical approach to measure the efficacy of anthelmintic treatment on horse farms. Parasitology. 2007;134:2027-39.

63. Kaplan RM, Nielsen MK. An evidence-based approach to equine parasite control: it ain't the 60s anymore. Equine Vet Educ. 2010;22:306-16.

64. Larsen ML, Ritz C, Petersen SL, Nielsen MK. Determination of ivermectin efficacy against cyathostomins and Parascaris equorum on horse farms using selective therapy. Vet J. 2011;188:44-7.

65. van Doorn DCK, Kooyman FNJ, Eysker M, Hodgkinson JE, Wagenaar JA, Ploeger HW. In vitro selection and differentiation of ivermectin resistant cyathostomin larvae. Vet Parasitol. 2010;174:292-9.

66. Traversa D, lorio R, Klei TR, Kharchenko VA, Gawor J, Otranto D, Sparagano $\mathrm{OA}$. New method for simultaneous species-specific identification of equine strongyles (Nematoda, Strongylida) by reverse line blot hybridization. J Clin Microbiol. 2007:45:2937-42.

67. Cwiklinski K, Kooyman FNJ, van Doorn DCK, Matthews JB, Hodgkinson JE. New insights into sequence variation in the IGS region of 21 cyathostomin species and the implication for molecular identification. Parasitology. 2012;139:1063-73.

68. Piche CA, Kennedy MJ, Herbers HA, Newcomb KM. Comparison of ivermectin, oxibendazole, and pyrantel pamoate in suppressing fecal egg output in horses. Can Vet J. 1991;32:104-7.

69. Demeulenaere D, Vercruysse J, Dorny P, Claerebout E. Comparative studies of ivermectin and moxidectin in the control of naturally acquired cyathostome infections in horses. Vet Rec. 1997;141:383-6.

70. von Samson-Himmelstjerna G, Fritzen B, Demeler J, Schurmann S, Rohn K, Schnieder T, Epe C. Cases of reduced cyathostomin egg-reappearance period and failure of Parascaris equorum egg count reduction following ivermectin treatment as well as survey on pyrantel efficacy on German horse farms. Vet Parasitol. 2007;144:74-80.

71. Geurden T, van Doorn D, Claerebout E, Kooyman F, De Keersmaecker S, Vercruysse J, et al. Decreased strongyle egg re-appearance period after treatment with ivermectin and moxidectin in horses in Belgium, Italy and the Netherlands. Vet Parasitol. 2014;204:291-6.

72. Van Wyk J. Refugia - overlooked as perhaps the most potent factor concerning the development of anthelmintic resistance. Onderstepoort J Vet. 2001;68:55-67.

73. Matthee S, Krecek R, Milne S, Boshoff M, Guthrie A. Impact of management interventions on helminth levels, and body and blood measurements in working donkeys in South Africa. Vet Parasit. 2002;107:103-13.

74. Nielsen M. Sustainable equine parasite control: perspectives and research needs. Vet Parasit. 2012;185:32-44.

75. Lester H, Bartley D, Morgan E, Hodgkinson J, Stratford C, Matthews J. A cost comparison of faecal egg count directed anthelmintic delivery versus interval programme treatments in horses. Vet Rec. 2013;173:371.

76. Kooyman FNJ, van Doorn DCK, Geurden T, Mughini-Gras L, Ploeger HW, Wagenaar JA. Species composition of larvae cultured after anthelmintic treatment indicates reduced moxidectin susceptibility of immature Cylicocyclus species in horses. Vet Parasitol. 2016;227:77-84.

77. Blackhall WJ, Pouliot JF, Prichard RK, Beech RN. Haemonchus contortus: selection at a glutamate-gated chloride channel gene in ivermectin-and moxidectin-selected strains. Exp Parasitol. 1998;90:42-8.

78. Njue Al, Hayashi J, Kinne L, Feng XP, Prichard RK. Mutations in the extracellular domains of glutamate-gated chloride channel $\alpha 3$ and $\beta$ subunits from ivermectin-resistant Cooperia oncophora affect agonist sensitivity. J Neurochem. 2004;89:1137-47.

79. Dent JA, Smith MM, Vassilatis DK, Avery L. The genetics of ivermectin resistance in Caenorhabditis elegans. Proc Nat Acad Sci USA. 2000;97:2674-9.

80. Kotze AC, Hunt PW, Skuce P, von Samson-Himmelstjerna G, Martin RJ, Sager H, et al. Recent advances in candidate-gene and whole-genome approaches to the discovery of anthelmintic resistance markers and the description of drug/ receptor interactions. Int J Parasitol Drugs Drug Resist. 2014;4:164-84.
81. Lespine A, Ménez C, Bourguinat C, Prichard RK. P-glycoproteins and other multidrug resistance transporters in the pharmacology of anthelmintics: prospects for reversing transport-dependent anthelmintic resistance. Int J Parasitol Drugs Drug Resist. 2012;2:58-75.

82. Whittaker JH, Carlson SA, Jones DE, Brewer MT. Molecular mechanisms for anthelmintic resistance in strongyle nematode parasites of veterinary importance. J Vet Pharmacol Ther. 2017:40:105-15.

83. Chapman MR, Kearney MT, Klei TR. Equine cyathostome populations: accuracy of species composition estimations. Vet Parasitol. 2003;116:15-21.

84. Avramenko RW, Redman EM, Lewis R, Yazwinski TA, Wasmuth JD, Gilleard JS. Exploring the gastrointestinal "nemabiome": deep amplicon sequencing to quantify the species composition of parasitic nematode communities. PLoS One. 2015;10:e0143559.

\section{Submit your next manuscript to BioMed Central and we will help you at every step:}

- We accept pre-submission inquiries

- Our selector tool helps you to find the most relevant journal

- We provide round the clock customer support

- Convenient online submission

- Thorough peer review

- Inclusion in PubMed and all major indexing services

- Maximum visibility for your research

Submit your manuscript at www.biomedcentral.com/submit
) Biomed Central 